\title{
ON THE RELATION BETWEEN THE LENGTHS OF THE YARD AND THE METER.
}

By William A. Rogers.

$\mathrm{T}$ HE present determination of the length of the meter, expressed in terms of the yard, rests upon a combined yard and meter constructed by the writer in 1880 . The description of the method of construction employed, and of the authorities upon which the total lengths depend, will be found in the Proceedings of the American Academy of Arts and Sciences for I 882-83, Vol. XVIII. It will be useful to give here a brief recapitulation of the results there found.

(a) Diagram showing the form of the bronze bar $R_{2}$, the ingre dients of which are 16 parts of copper, $2 \frac{1}{2}$ parts of tin, and I part of zinc.

The inner circles, $a, b, c$, represent the polished surfaces of platinum-iridium plugs inserted in the metal. The lines traced
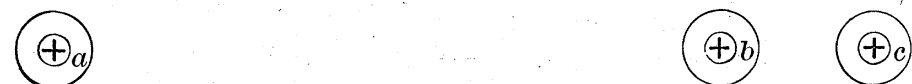

upon these plugs are protected by circles of thin cover-glass cemented to the surface of the metal by means of Canada balsam. These cover-glasses are represented by the larger circles.

(b) Corrections to the yard $(a b)$ and the meter $(a c)$ adopted in I 882.

$(a b)+.000008$ in. $=$ the Imperial Yard of Great Britain $=Y$;

$(a c)-\mathrm{I} .3 \mu=$ the Metre des Archives $=A_{0}$.

Coefficient of expansion of the bronze bar $R_{2}=17.17 \mu$ for each degree $\mathrm{C}$. 
(c) The meter depends on the following authorities :-

(I) A meter upon a copper bar having the $\mathrm{X}$ form, presented to the writer by the late Professor Tresca, who was at that time in charge of the Conservatoire des Arts et Metiers at Paris. This meter, designated $T$, was transferred by M. Tresca from a copy of the Metre des Archives, designated "No. 19," which was at that time provisionally adopted as the equivalent of the original standard. The transfer was made at two o'clock in the morning of February 6 , 1880. From subsequent comparisons it appeared that -

and $\quad T$ - I $18.9 \mu=$ Metre des Archives at $0^{\circ} \mathrm{C}$.

(2) An end-measure meter by Foment $=F$, of which the following relation to $A_{0}$ had been found:-

$$
F-8.4 \mu=A_{0} \text { at } 0^{\circ} \mathrm{C} \text {. }
$$

(3) A combined yard and meter upon brass, made at the Bureau of Weights and Measures, Washington, and now in the possession of the Stevens Institute. The meter upon this bar, which is designated $C S$, was in 1883 compared with the provisional standard at that time adopted at the International Bureau of Weights and Measures with the resulting relation:-

$$
C S+310 \mu=A_{0} \text { at } 0^{\circ} \mathrm{C} \text {. }
$$

(4) A meter belonging to the United States Coast Survey, known as the Berlin meter "No. 49," for which the following relation is given by Foester :-

$$
\text { “No. } 49 "+2 \mathrm{I} .4 \mu=A_{0} \text { at } 0^{\circ} \mathrm{C} \text {. }
$$

The yard upon $R_{2}$ depends upon the following authorities:-

(I) A yard $R_{n}$ upon nickel-plated steel made by the writer in I 880, and compared with $Y$ by Mr. H. J. Chaney, the Warden of the Imperial Standards.

$$
R_{n}+.000316 \text { in. }=Y \text { at } 62^{\circ} .
$$

(2) A yard upon the brass bar $C S$, also compared with $Y$ by Mr. Chaney.

$$
C S+.00008 \mathrm{I} \text { in. }=Y \text { at } 62^{\circ} .
$$


(3) The yard of the United States Bureau of Weights and Measures known as "Bronze I I."

"Bronze I I" +.000088 in. $=Y$ at $62^{\circ}$.

Two values of the relation between the relative lengths of the yard and the meter have been published by the writer. The first one is given on page 398 of the Proceedings of the Academy, viz.:-

$$
Y+3.37027 \text { in. }=A_{0} \text { at } 62^{\circ} .
$$

During the year I 887 the writer constructed for the Standards' Department of the London Board of Trade a combined yard and meter upon a bar of Baily's metal, which was transmitted by $\mathrm{Mr}$. Chaney for this purpose. Before this standard, designated $C_{2}$, was returned to London it was compared with $R_{2}$, with the following results :-

\begin{tabular}{c|c|c|c}
\hline \multicolumn{3}{|c|}{ FOR THE METER. } & FOR THE YARD. \\
\hline $\begin{array}{c}\text { No. of } \\
\text { Comparisons. }\end{array}$ & $\tau$ & $R_{2}-C_{2}$ & $R_{2}-C_{2}$ \\
\hline$\varepsilon$ & & $-2.7 \mu$ & $-0.1 \mu$ \\
9 & $31.66^{\circ}$ & -2.3 & -1.2 \\
9 & 33.83 & -1.7 & -0.2 \\
8 & 40.42 & -1.7 & +0.8 \\
8 & 47.52 & -2.9 & -0.8 \\
\hline & 72.75 & -2.26 & -0.30 \\
\hline
\end{tabular}

Soon after the arrival of the standard at London a series of comparisons with the Imperial yard was made by Mr. Chaney. The results are given on page 7 of the Report to the Board of Trade for $1886-88$, from which it appears that -

$$
C_{2}+\text {.000I } 28 \text { in. }=Y \text {. }
$$

Since $C_{2}-.0000 \mathrm{I} 2=R_{2}$, we have $R_{2}+$.000I 40 in. $=Y$.

The original relation given must therefore be corrected by $+.000132 \mathrm{in}$. and the relation between the length of the yard and the meter is -

$$
Y+3.37014 \text { in. }=A_{0}
$$


A remeasurement of the distance ( $b c)$ made at this time, the details of which are omitted, gave, using the new correction to $R_{2}$, -

$$
Y+3.37012 \text { in. }=A_{0} \text {. }
$$

This value was communicated to Professor Hazen of the Signal Office at Washington and was made the basis of the linear measure tables in his Handbook of Meteorological Tables, published in I888. In the letter in which this result was communicated, the writer somewhat incautiously expressed the opinion that the true relation would be found to fall between the limits 39.37012 in. and $39.37015 \mathrm{in}$. In the preface to the volume, the first value is erroneously printed 39.3702 in. With the limitation that the corrections to the yard and the meter of $R_{2}$ are correctly given, this statement will probably be found to hold nearly true.

In view of the importance of a direct measurement of the space $(b c)$ without the interference of the cover-glasses, it was decided to transfer to the edge of $R_{2}$ a new yard and meter, and in order that the conditions of comparison might vary as widely as possible, a provisional yard and meter were first laid off with the following subdivisions :-

Meter designated $R_{2 e_{1}}=(a c)$. Yard designated $R_{2 e_{1}}$ was subdivided into 9 equal parts. Two separate 4 -inch spaces were subdivided to inches, and the last inch to tenths of inches. The space from 3.3 in. to 3.4 in. was further subdivided into ro equal parts, thus allowing a direct comparison of the space $(b c)$ with the nearest hundredth of an inch. These auxiliary scales are designated $4 i_{1}$ and $4 i_{2}$. After the entire investigation had been completed, a second transfer was made to the other edge of the bar in which the 4-inch subdivisions of the yard were given rather large periodic errors. A new 4-inch space was also laid off. The former is designated $R_{2 e_{2}}$ and the latter $4 i_{3}$.

The determination of the true value of $(b c)$ consists of three operations, viz.:-

(a) The measure of the true value of the space $4 i$ obtained by comparing it with each of the 4-inch spaces of the yard, corrected for the amount of the error in the total length. The correction for the line 3.37 in. will thus become known. 
(b) The comparison of the space $(b c)$ with the $4 i$ space, the deviation from the distance 3.37 in. being measured with the micrometer of the microscope.

(c) The subtraction from the measured value of $(b c)$ of the algebraic sum of the corrections to the distances $(a c)$ and $(a b)$. Thus, since the meter of $R_{2}$ is I. $3 \mu$ too long, and the yard is .00014 in. too short, the space $(b c)$ will be .000Ig in. too long.

The results, expressed in divisions of the micrometer, of the different measurements of the space $(b c)$, are given below. One division of micrometer $=.203 \mu=.000008 \mathrm{in}$.

I. Measurement of $(b c)$ in terms of a 4-inch scale upon speculum metal. This scale has the last inch subdivided into Ioo equal parts.

II. Measurement of $(b c)$ in terms of a decimeter subdivided to millimeters, with the last millimeter subdivided to tenths of millimeters. For a description of these scales, see Astronomical Journal, No. $28 \mathrm{r}$.

\begin{tabular}{|c|c|c|c|c|}
\hline \multicolumn{2}{|r|}{ Date. } & $\mathbf{T}$ & $\begin{array}{l}\text { I. } \\
\text { Excess over } 3.37 \text { in. } \\
\text { at } 62^{\circ} .\end{array}$ & $\begin{array}{c}\text { II. } \\
\text { Excess over } 85.6 \mathrm{~mm} \text {. } \\
\text { at } 62 .\end{array}$ \\
\hline \multirow[t]{2}{*}{1893} & $\begin{array}{cc}\text { Jan. } & 14 \\
\text { “ } & 15 \\
\text { “ } & 15 \\
\text { “ } & 16 \\
\text { “ } & 17 \\
\text { “ } & 18 \\
\text { “ } & 19 \\
\text { “ } & 19 \\
\text { “ } & 20 \\
\text { “ } & 21 \\
\text { “ } & 22\end{array}$ & $\begin{array}{l}40.3^{\circ} \\
49.5 \\
56.3 \\
57.8 \\
50.6 \\
61.8 \\
62.0 \\
68.6 \\
50.8 \\
46.4 \\
36.0\end{array}$ & $\begin{array}{l}-49.3 \text { div. } \\
-45.0 \\
-48.6 \\
-48.4 \\
-44.6 \\
-45.0 \\
-46.2 \\
-48.4 \\
-48.6 \\
-43.2 \\
-45.7\end{array}$ & $\begin{array}{l}-37.7 \text { div. } \\
-35.7 \\
-34.1 \\
-34.1 \\
-39.1 \\
-33.8 \\
-33.3 \\
-34.4 \\
-34.1 \\
-35.9 \\
-33.6\end{array}$ \\
\hline & & & means -46.6 & -35.1 \\
\hline
\end{tabular}

I. Measured excess over 3.37 in. . . . . . $\quad-46.6$ div. Space $(b c)$ too long . . . . . . . . . . +24.0

Correction to line 3.37 in. . . . . . . +3.5

Excess over 3.37 in. . . . . . . . . . . -19.1

$(b c)=3.370153 \mathrm{in}$.

II. Measured excess over $85.600 \mathrm{~mm}$. . . . $\quad-35.1$ div.

Space $(b c)$ too long . . . . . . . . . . +24.0

Correction to line $85.6 \mathrm{~mm}$. . . . . . . . +1.8

Excess over $85.6 \mathrm{~mm}$. . . . . . . . . . $\quad-9.3$

$(b c)=85.60186 \mathrm{~mm} .=3.370154 \mathrm{in}$. 
III. Measurement of $(b c)$ of $R_{2}$ and of $(b c)$ of $R_{2 e_{1}}$ in terms of $4 i_{1}$ and $4 i_{2}$.

Relations FOR TOTAL Length.

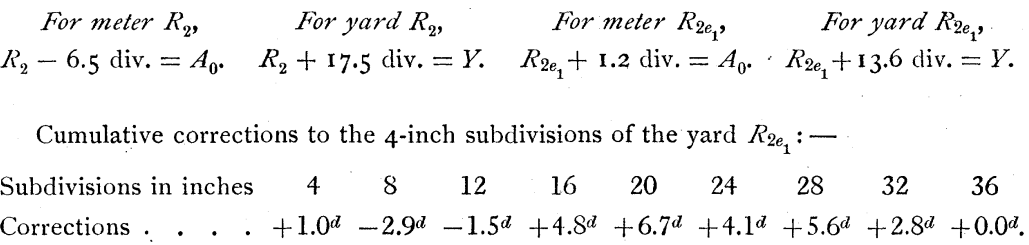

\section{CORRECTIONS TO SPACES $4 i_{1}$ AND $4 i_{2}$.}

In the following tables the first column represents the summed series of corrections to the separate inches which are marked [ ], and the distributed corrections for each tenth of the fourth inch. The second column contains the corrections to the 4-inch space due to the error in total length. The third column contains

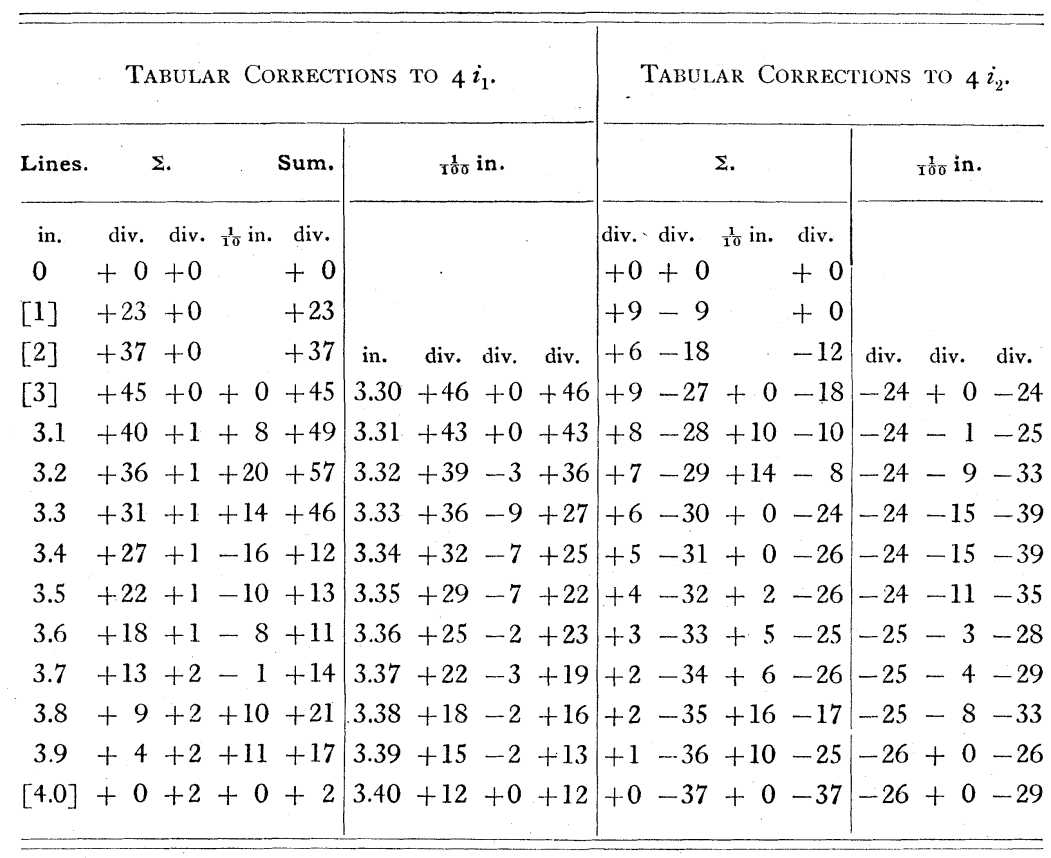


Spaces $\left(b c\right.$ ) in Terms of the Corrected Values of $4 i_{1}$ and $4 i_{2}$.

\begin{tabular}{|c|c|c|c|c|}
\hline Date. & From $R_{2}$ & From $R_{2 e_{1}}$. & From $R_{2}$. & From $R_{2 e_{1}}$. \\
\hline Jan. 30. & -58.8 div. & -12.2 div. & -49.5 div. & -2.9 div. \\
\hline “ 31. & -66.8 & -15.1 & -60.3 & -6.4 \\
\hline Feb. 1. & -64.1 & -11.7 & -55.6 & -3.2 \\
\hline " 1. & -65.4 & -15.2 & -56.0 & -5.8 \\
\hline “ 1 . & -60.2 & -12.5 & -54.9 & -4.8 \\
\hline " 2 & -59.4 & -9.8 & -49.0 & +0.6 \\
\hline Means. & -62.4 & -12.7 & -54.2 & -3.7 \\
\hline ons to $(b c)$. . . & +24.0 & +24.0 & +12.4 & +12.4 \\
\hline ons to line $3.37 \mathrm{in}$. & +19.0 & -29.0 & +19.0 & -29.0 \\
\hline ver $3.37 \mathrm{in..} \mathrm{.} \mathrm{.}$ & -19.4 & -17.7 & -22.8 & -20.3 \\
\hline$n$ parts of an inch. & -.000155 & -.000142 & -.000182 & -.000162 \\
\hline
\end{tabular}

the corrections to the $\frac{1}{10}$-inch subdivisions of the fourth inch. The fourth column is formec by taking the sum of the three previous columns. The subsidiary tables contain the corrections to the lines from $3.30 \mathrm{in}$. to $3.40 \mathrm{in}$. The correction to line $3.37 \mathrm{in.}$ is required.

IV. Measurement of $(b c)$ of $R_{2}$ and of $R_{2 e_{2}}$ in terms of $4 i_{3}$.

In order to introduce a wide variation in the conditions of comparison, the corrections are given for both edges of the terminal lines of the yard and the meter $R_{2 e_{2}}$.

Relations For TOtal Length.

\begin{tabular}{|c|c|c|c|}
\hline \multicolumn{2}{|c|}{$\begin{array}{l}\text { For the right edge of the } \\
\text { terminal line of - }\end{array}$} & \multicolumn{2}{|c|}{$\begin{array}{l}\text { For the left edge of the } \\
\text { terminal line of - }\end{array}$} \\
\hline The meter. & The yard. & The meter. & The yard. \\
\hline$R_{2 e_{2}}-6.2$ div. $=A_{0}$ & $R_{2 e_{2}}+0.1$ div. $=Y$ & $R_{2 e_{2}}-49.5$ div. $=A_{0}$ & $R_{2 e_{2}}-37.0$ div. $=Y$ \\
\hline \multicolumn{4}{|c|}{ Cumulative corrections to the 4 -inch divisions of the yard $R_{2 e_{2}}:-$} \\
\hline Subdivisions in inches & $\begin{array}{llll}5 & 4 & 8 & 12\end{array}$ & $2 \quad 16 \quad 20 \quad 24$ & 28 \\
\hline
\end{tabular}


[Vol. İ.

\begin{tabular}{|c|c|c|c|}
\hline 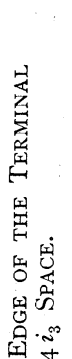 & 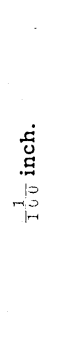 & 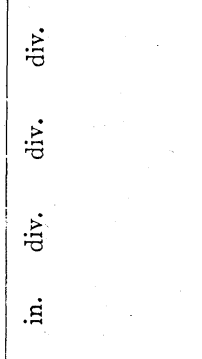 & 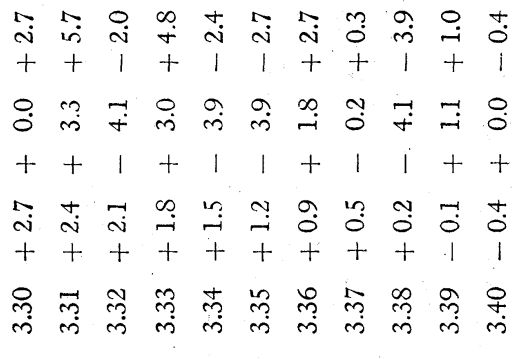 \\
\hline 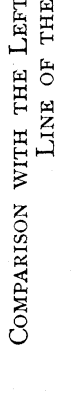 & 皃 & 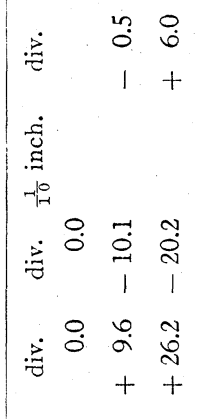 & 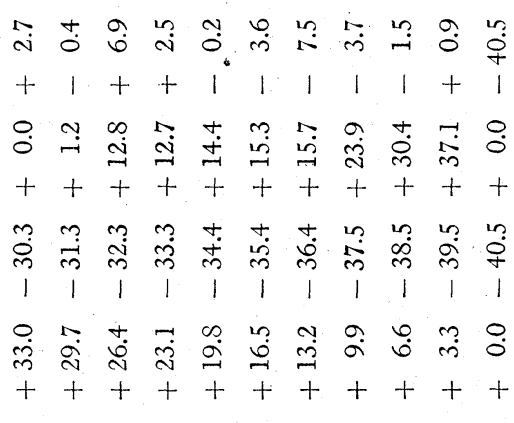 \\
\hline 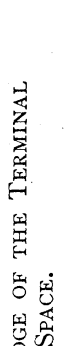 & & $\begin{array}{l}\dot{\vec{g}} \\
\dot{\vec{g}} \\
\dot{\vec{g}} \\
\dot{\dot{g}}\end{array}$ & 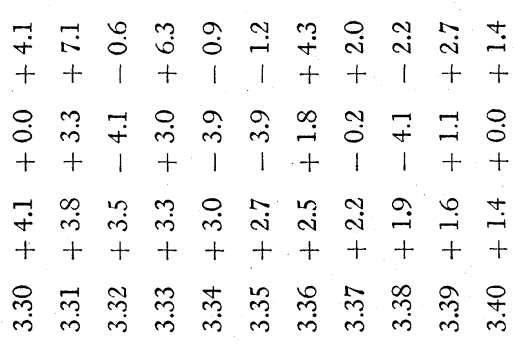 \\
\hline 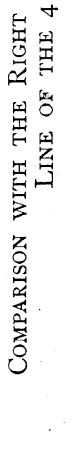 & $\dot{w}$ & 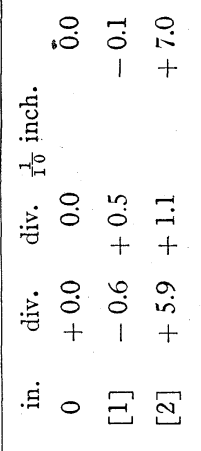 & 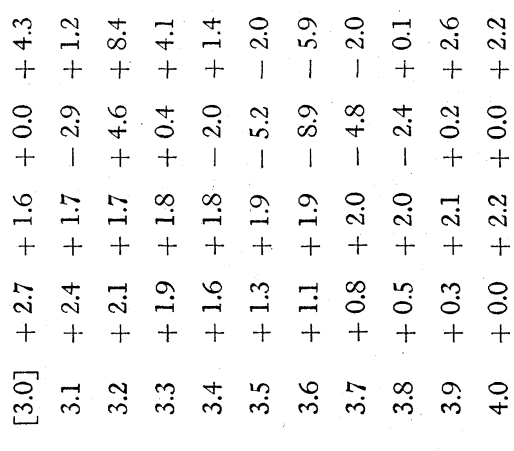 \\
\hline
\end{tabular}


Spaces $\left(b c\right.$ ) in Terms of the Corrected Value of $4 i_{3}$.

\begin{tabular}{|c|c|c|c|c|c|}
\hline Date. & $R_{2}-4 i_{3}$ & $R_{2 e_{2}}-4 i_{3}$ & $\begin{array}{l}R_{2}-4 i_{3} \\
\text { Left edge. }\end{array}$ & $\begin{array}{l}R_{2 e_{2}}-4 i_{3} . \\
\text { Right edge of } \\
\text { line for meter. } \\
\text { Left edge of } \\
\text { line for yard. }\end{array}$ & $\begin{array}{l}R_{2 e_{2}}-4 i_{3} . \\
\text { Left edge of } \\
\text { line for meter. } \\
\text { Right edge of } \\
\text { line for yard. }\end{array}$ \\
\hline $\begin{array}{cc}\text { Feb. } & 27 \\
\text { “ } & 28 \\
\text { “ } & 28 \\
\text { “ } & 28 \\
\text { “ } & 29 \\
\text { “ } & 29 \\
\text { “ } & 29 \\
\text { Mar. } & 1 \\
\text { “ } & 1\end{array}$ & $\begin{array}{l}-49.9 \text { div. } \\
-48.0 \\
-45.6 \\
-44.0 \\
-44.2 \\
-48.2 \\
-45.1 \\
-47.6 \\
-43.4\end{array}$ & $\begin{array}{l}-27.0 \text { div. } \\
-30.9 \\
-29.4 \\
-28.8 \\
-24.9 \\
-24.0 \\
-24.9 \\
-26.7 \\
-24.8\end{array}$ & $\begin{array}{l}-33.9 \text { div. } \\
-32.8 \\
-33.0 \\
-37.2 \\
-36.6 \\
-34.9 \\
-29.7 \\
-32.4 \\
-31.9\end{array}$ & $\begin{array}{l}+10.7 \text { div. } \\
+11.0 \\
+14.0 \\
+16.8 \\
+16.2 \\
+13.8 \\
+11.5 \\
+11.8 \\
+17.3\end{array}$ & $\begin{array}{l}-70.1 \text { div. } \\
-68.8 \\
-67.5 \\
-72.2 \\
-63.0 \\
-67.9 \\
-65.7 \\
-69.1 \\
-70.0\end{array}$ \\
\hline $\begin{array}{l}\text { Means. } \\
\text { Corrections to }(b c) . . \\
\text { Correction of line } 3.37 \text { in. } \\
\text { Excess over } 3.37 \text { in. } \\
\text { Excess in parts of an inch. }\end{array}$ & $\begin{array}{l}-46.2 \\
+24.0 \\
+1.1 \\
-21.1 \\
-.000169\end{array}$ & $\begin{array}{l}-26.8 \\
+6.3 \\
+1.1 \\
-19.4 \\
-.000155\end{array}$ & $\begin{array}{l}-33.6 \\
+12.5 \\
+1.1 \\
-20.0 \\
-.000160\end{array}$ & $\begin{array}{l}+13.7 \\
-30.8 \\
+1.1 \\
-16.0 \\
-.000128\end{array}$ & $\begin{array}{l}-68.3 \\
+49.6 \\
+1.1 \\
-17.6 \\
-.000141\end{array}$ \\
\hline
\end{tabular}

Adopting the mean of the I I determinations, we have finally:-

$$
Y+3.370155 \text { in. }=A_{0} \text {. }
$$

Dr. Gould, in his annual address before the American Meteorological Society, gives for the result of the latest determination at Breteuil :-

$$
Y+3.37000 \text { in. }=A_{0} .
$$

It is to be noted, however, that this determination is the result of only secondary comparisons through the toise. If this relation should eventually be found to be true, meter $R_{2}$ would require a further correction of $-3.9 \mu$, on the supposition that the correction for the yard is correctly given.

Shannon Physical Laboratory, Colby University, March 29, 1893 . 